\title{
DESLIZANDO PELAS CATEGORIAS SÍGNICAS DE C. S. PEIRCE: UM ESTUDO DE CASO
}

\author{
Sliding through sign categories of C. S. Peirce: a case study \\ Deslizamiento por las categorías sígnicas de C. S. Peirce: un \\ estudio de caso
}

\section{Priscila Borges}

Universidade de Brasília, Brasília, Distrito Federal, Brasil.

Professora do Departamento de Audiovisuais e Publicidade da Faculdade de Comunicação da Universidade de Brasília e do Programa de Pós-Graduação em Comunicação da Universidade Federal de Ouro Preto. Doutora e mestre em Comunicação e Semiótica pela Pontifícia Universidade Católica de São Paulo.

E-mail: primborges@gmail.com

\section{Marcelo Santos}

Faculdade Cásper Líbero, São Paulo, Brasil.

Professor permanente do Mestrado em Comunicação da Faculdade Cásper Líbero. Doutor e mestre em Comunicação e Semiótica pela Pontifícia Universidade Católica de São Paulo.

E-mail: masmoraes@casperlibero.edu.br

RESUMO Ao apropriar-se, fonética e graficamente, da fórmula da água (o legissígno simbólico $\mathrm{H} 2 \mathrm{O}$ ), a marca de refrigerantes $\mathrm{H} 2 \mathrm{OH}$ ! adotou uma estratégia semiótica peculiar: deslocou um signo predominantemente de terceiridade para a primeiridade, habilitando-o a gerar, preferencialmente, interpretantes na esfera qualitativa-sugestiva. Neste trabalho, fazemos a análise semiótica da marca grafada no rótulo da bebida, com enfoque nos interpretantes da divisão dos signos em dez tricotomias.

PALAVRAS-CHAVE Deslizamento de categoria, Símbolo, Interpretante, Semiótica aplicada, Marca.

ABSTRACT The soft drink "H2OH!" adopted a peculiar semiotic strategy to present its product. The brand assumes in phonetical and graphical terms the water formula, displacing it from thirdness to firstness, enabling it to generate, preferably, interpretants in a qualitative-suggestive scope. In this work, we present a semiotic analysis of the brand written on the beverage label, focusing on the interpretants of ten trichotomies.

KEYWORDS Category sliding, Symbol, Interpretant, Applied semiotics, Brand mark.

RESUMEN Cuando la marca de refrescos $\mathrm{iH} 2 \mathrm{OH}$ ! se apropió del sonido y de la escrita de la fórmula del agua, el legisigno simbólico H2O, adoptó una estrategia semiótica peculiar: desplazó un signo predominantemente de terceridad para la primeridad; y este signo creado genera interpretantes, sobretodo en la esfera cualitativa-sugerente. En este trabajo, presentamos el análisis semiótico de la referida marca, centrándonos en los interpretantes de la división de los signos y diez tricotomías.

PALABRAS CLAVE Desplazamiento de Categoría, Símbolo, Interpretante, Semiótica Aplicada, Marca. 


\section{INTRODUÇÃO}

Trabalhamos pela primeira vez este material na Jornada Peirceana de 2010, evento promovido pelo Centro Internacional de Estudos Peirceanos, da PUC-SP. Aqui, apresentamos versão revisada e ampliada do artigo apresentado naquela ocasião, colocando acento na divisão dos signos em dez tricotomias e nos três interpretantes pertencentes a essa classificação: imediato, dinâmico e final. Trabalhamos especialmente com as seis tricotomias que envolvem tais interpretantes e que dizem respeito tanto aos interpretantes em si mesmos quanto às relações que eles podem estabelecer com o signo. Esperamos, assim, exemplificar aquilo que nomeamos "deslizamento de categoria”.

Nosso objeto de estudo é a bebida $\mathrm{H} 2 \mathrm{OH}$ !, lançada nos Estados Unidos no ano de 1988 e trazida ao Brasil em setembro de 2006 por uma parceria das empresas PepsiCo e Ambev. Três meses após o início de sua comercialização, a H2OH! já respondia por $10 \%$ do mercado nacional de refrigerantes (O “light”..., 2007). O sucesso foi tamanho que, em alguns lugares, conforme noticia a matéria publicada no jornal $O$ Globo de 18 de maio de 2007, a demanda pelo produto gerou desabastecimento. ${ }^{1}$

Além do êxito mercadológico, o début da “H2OH!” no Brasil também esteve associado a uma extensa e curiosa batalha nos tribunais: a Associação Brasileira da Indústria de Água Mineral (Abinam) solicitou o cancelamento de registro e retirada de circulação da bebida, argumentando que

O produto, além de ter um nome que induz à crença de que se trata de uma água, fica exposto nos supermercados na seção das águas, mas não pode ser assim classificado por causa de sua composição. No rótulo da $\mathrm{H} 2 \mathrm{OH}$ ! está especificado se tratar de refrigerante de limão de baixa caloria. O objetivo, segundo a Abinam, é proteger o consumidor, o qual deve ter acesso a informações corretas. A PepsiCo se defende, no entanto, alegando que a legislação não possui classificação para água saborizada, daí a necessidade de encontrar outra definição, que no caso da companhia foi refrigerante. [...] $\mathrm{O}$ rótulo da $\mathrm{H} 2 \mathrm{OH}$ ! informa que o produto é composto por “água levemente gaseificada, sem açúcar, com vitamina B e suco natural de limão”. (Pepsico..., 2006)

A proximidade entre o nome da bebida e a fórmula química da água é tão grande que, em 2009, a Advocacia Geral da União (AGU), segundo o site da Instituição (agu.gov.br), precisou intervir contra uma ação ajuizada pelo Ministério Público Federal contra a AmBev, acusada de vender um produto "enganoso". A defesa promovida pela AGU, em favor do Instituto Nacional da Propriedade Industrial, que concedeu registro para a marca “H2OH!”, foi a de que “o acréscimo da letra 'H' e do ponto de exclamação (!), ao símbolo H2O, diferenciava a marca do símbolo da água”. ${ }^{2}$

Há, a despeito das questões jurídicas, químicas e mercadológicas citadas, um peculiar objeto semiótico: através de seu nome, quase que em homofonia com a fórmula do solvente universal, a marca “H2OH!”, explicitaremos, passa não só a se remeter à água, mas a gerar

1. Disponível em: <https://glo.bo/2o6AwCD>. Acesso em: 7 abr. 2017.

2. Disponível em: <http://bit.ly/2o6WBBn>. Acesso em: 7 abr. 2017. 
interpretantes em nível qualitativo-sugestivo inesperados para a notação científica à qual faz referência ${ }^{3}$.

A seguir, resumidamente, procederemos a uma análise semiótica dos aspectos visuais presentes na marca $\mathrm{H} 2 \mathrm{OH}$ ! a partir da assinatura encontrada no rótulo da embalagem de $500 \mathrm{ml}$ do produto, comercializada em junho de 2010. Para tanto, seguiremos o roteiro metodológico proposto por autores como Santaella (2002), Santaella e Nöth (2010), Araújo (2004; 2005) e Chiachiri $(2004 ; 2006)$.

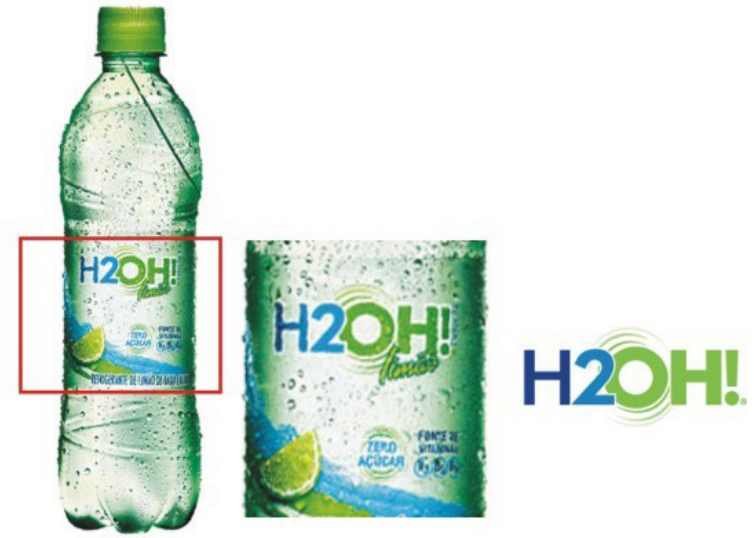

Figura 1. Rótulo H2OH!

\section{ASPECTOS QUALITATIVOS-ICÔNICOS}

\section{Cor}

Existem dois tons (brilho relativo) de azul e um de verde (ver Figura 2).

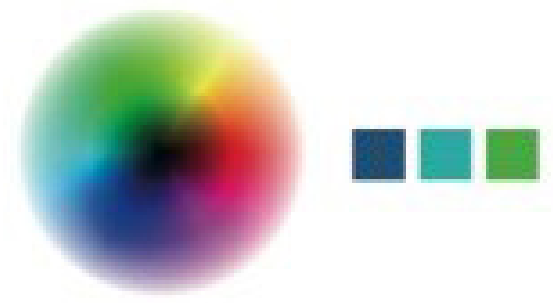

Figura 2. Círculo cromático.

3. Apenas a título informativo, adicione-se que a $\mathrm{H} 2 \mathrm{OH}$ foi legalmente obrigada a parar de ser vendida na seção de águas dos supermercados, sendo hoje comercializada na gôndola dos refrigerantes; segundo dados da Advocacia Geral da União (agu.gov.br), “com o intuito de esclarecer a comunidade diante da confusão entre as águas engarrafadas e a $\mathrm{H} 2 \mathrm{OH}$ !, chegaram a ser celebrados Termos de Ajustamento de Conduta por meio dos quais as empresas se comprometeram a aumentar o tamanho das letras da denominação que explica a natureza do produto. As fabricantes prometeram, ainda, recomendar às grandes redes de supermercado e à Associação Paulista dos Supermercados (APAS) que não divulgasse os produtos como se fossem água”. Disponível em: <http://bit.ly/206WBBn>. Acesso em: 7 abr. 2017. 
Como podemos observar, um dos tons de azul é escuro, enquanto o outro, assim como o verde, é luminoso. No círculo cromático ${ }^{4}$, percebe-se que os tons encontrados situam-se próximos, conferindo, portanto, um efeito harmônico. Adicione-se que, apesar do azul e do verde serem cores predominantemente frias, o tom claro de azul seguido pelo tom cítrico de verde cria um efeito levemente aquecido, sugerindo uma nota de frescor, a sensação de refrescância, e não de frio (ver Figura 3).

Por fim, cumpre dizer que, cromaticamente, há a presença de neutralidade (menor saturação de um dos tons de azul), mas também de maior emoção e intensidade (azul e verde mais saturados), sendo esta última predominante.

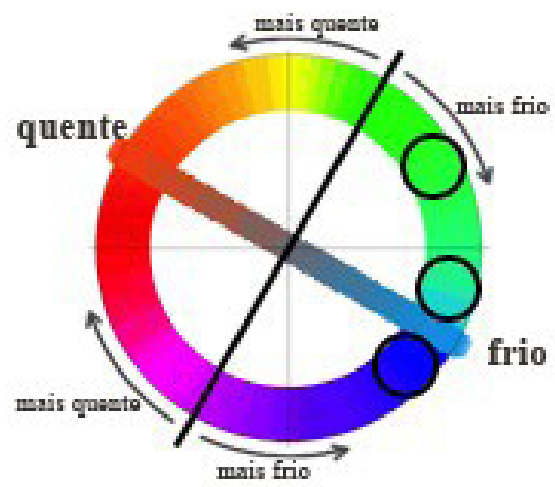

Figura 3. Temperatura no círculo cromático

\section{Textura}

A textura visual é lisa em toda a experiência, evocando harmonia e continuidade.

\section{Forma}

Pode ser observada a presença de formas simples, tanto retilíneas quanto orgânicas. A presença do contorno branco entre as formas possibilita que cada elemento seja visto em separado, comunicando não apenas em conjunto, mas também individualmente. Destaque para as formas circulares verdes centrais que dão a sensação de movimento.

\section{Opacidade}

No rótulo, a marca apresenta-se opaca, impressa sobre material semitransparente, levemente esverdeado, sugerindo limpidez, pureza

4. O "círculo cromático" é também conhecido por nomes como "disco das cores" ou "disco de Newton" (Goldman, 1964, p. 159). Na sua obra Doutrina das cores, Goethe (apud Giannotti, 1996, p. 170-171) apresenta o círculo cromático como um diagrama lógico para a compreensão das relações entre as cores a partir de suas polaridades, o que permite uma divisão em cores primárias, secundárias e terciárias, ou ainda em cores complementares, análogas, opostas, e assim por diante. São categorias que, por exemplo, dão elementos para pensar a impossibilidade de o púrpura e o verde produzirem cor intermediária; "Wittgenstein discute essas questões quando pergunta se podemos pensar um vermelho-esverdeado" (Giannotti, 1996, p. 172). Em desenvolvimentos posteriores, as órbitas cromáticas também passaram a ser associadas a características como temperatura (Goldman, 1964, p. 162). 
e interpenetrância (é possível visualizar o líquido no interior da embalagem). É quase como se a marca estivesse dentro da bebida.

\section{Dimensão}

Apesar da marca chapada, duas camadas distintas são sugeridas: uma azul, em primeiro plano, e uma verde. A marca parece pequena.

\section{Sensação geral}

As gradações tonais próximas, a textura lisa e uniforme, a semitransparência e a simplicidade das formas criam um efeito de harmonia e leveza na marca, com um leve toque refrescante.

\section{ASPECTOS SINGULARES-INDICIAIS}

\section{Cor}

Nas cores presentes na marca, encontra-se uma decomposição em quadricromia ${ }^{5}$ particular (ver Figura 4).
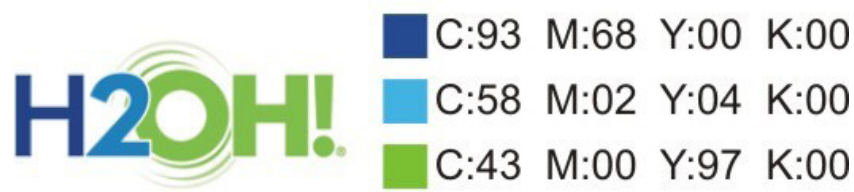

Figura 4. Quadricromia aproximada das cores usadas na marca $\mathrm{H} 2 \mathrm{OH}$ !

Constata-se que o pigmento preto não é usado, e que, à exceção da primeira cor decomposta, as demais apresentam teores medianos, próximos aos 50\%, para o cyan. Isso demonstra que tanto o segundo azul quanto o verde são cores luminosas; o verde especialmente, com cerca de $97 \%$ de concentração de amarelo.

\section{Textura}

Verifica-se a textura de um material plástico, que é liso e leve tanto visualmente quanto ao toque. A ausência de texturas gráficas além da lisa faz com que a atenção fique toda concentrada no cromatismo, informação visual mais importante da marca.

5. "O gravador alemão Jackob Christof Le Blon, em seu tratado Colloritto, publicado em 1725, define que podemos representar todos os objetos visíveis com três cores (vermelho, amarelo e azul), todas as outras cores podem ser compostas destas três e que a mistura destas três produz o preto. No entanto, foi Goethe quem propôs a substituição do vermelho pelo púrpura e do azul pelo azul-esverdeado para compor a tríade primária das corespigmento. Em 1936, a Agfa e a Kodak padronizaram os nomes destas cores criando a cor magenta para denominar o púrpura primário e o cyan (ou ciano) para denominar o azul-esverdeado. Nos anos 50, a Deutsches Institut für Normung (DIN) define as cores magenta amarelo e cyan como as cores básicas de impressão [...]. Considerando que os pigmentos têm certo grau de impureza, foi acrescentado o reforço do preto como a quarta cor de impressão” (Guimarães, 2000, p. 64-65). 


\section{Forma}

Constata-se a existência de componentes verbais, a saber, letras, um número e um sinal de pontuação, assim como elementos circulares exclusivamente gráficos, que indicam um movimento da direita para esquerda.

Quanto à distribuição das formas, conforme pode ser observado (Figura 5), existe um ligeiro desequilíbrio, com maior concentração de massa gráfica do lado direito e na porção inferior da marca; estão nessas áreas, pois, a maior quantidade de formas gráficas.

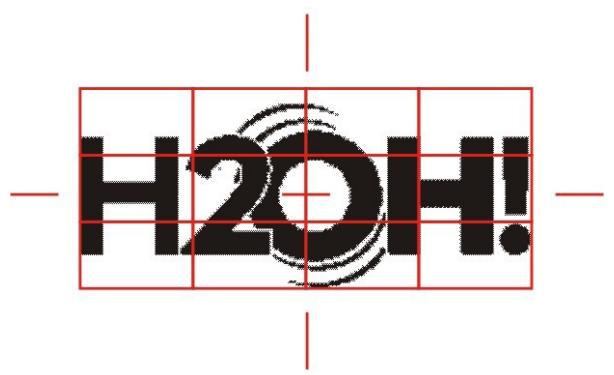

Figura 5. Malha gráfica da marca.

\section{Opacidade}

A opacidade da marca impressa é de 100\%, indicando-a como um elemento importante, para ser visto em integridade. O rótulo é feito em plástico transparente, que adquire tom esverdeado em função da cor da garrafa que recobre.

\section{Dimensão}

A área ocupada pela marca é a de um retângulo com $10,34 \mathrm{~cm}^{2}$. A volumetria, por tratar-se de um objeto bidimensional, é irrelevante.

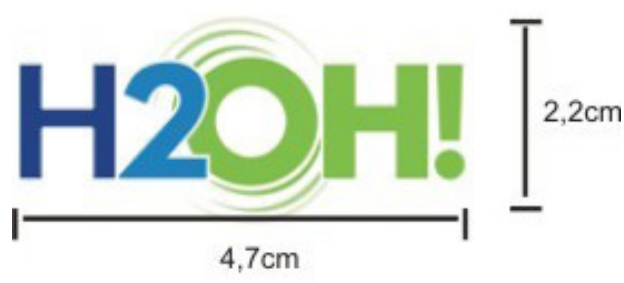

Figura 6. Dimensão da marca $\mathrm{H} 2 \mathrm{OH}$ !

\section{Descrição geral}

Pela ausência de preto em sua composição e pela grande concentração de amarelo em seu hemisfério direito, trata-se de um objeto predominantemente luminoso. A textura é, de fato, leve e lisa, pois a marca é impressa em um fino material plástico, do qual se destaca por ser opaca. Apesar de objetivamente não existir equilíbrio, esse efeito é conseguido pela distribuição quase homogênea das formas, com um leve peso gráfico na porção direita inferior, indicando que, nessa área, está localizada a informação visual mais relevante. A área de $10,34 \mathrm{~cm}^{2}$ possibilita a leitura rápida, isto é, que toda a marca seja vista de uma única vez. 


\section{ASPECTOS SIMBÓLICOS}

\section{Cor}

Desenha-se um percurso que vai da neutralidade (menor saturação do primeiro tom de azul) a um estado de maior emoção e intensidade (azul e verde mais saturados), o que pode se explicar pelo hábito ocidental de leitura da esquerda para a direita. Sabendo-se que o produto representado é uma bebida comercial, composta, segundo o fabricante, por "água levemente gaseificada e suco natural de limão", pode-se ler que a cor azul esteja se remetendo simbolicamente à água, e a cor verde, ao limão; é um produto, logo, que se desloca entre o "neutro aquoso" e o "emocionante cítrico", conservando essas duas características. Não se trata de uma emoção qualquer, mas de uma emoção com segurança, garantida pela presença sóbria do primeiro tom de azul.

É importante notar que, cromaticamente, ficam sugeridas duas interpretações: na primeira, leem-se separados os dois tons de azul e o tom de verde, como dois blocos de signos. Na segunda, secciona-se a marca em "H” (menos saturação) e "2OH!" (mais saturação), simbolizando que o número "2", mesmo azulado, pertence ao hemisfério de emoção da marca (seria o numeral o símbolo de uma água emocionante - ou emocionada - pelo contato com o limão)?

\section{Textura}

Como relatado, a textura lisa que acompanha toda a marca acaba dando destaque ao cromatismo, símbolo gráfico principal do produto. Ao mesmo tempo, o liso refere-se a algo contemporâneo, simples, sem imperfeições e, fazendo correlações etimológicas, tem-se que liso origina "lisura” e, assim, "correção", "confiabilidade”.

\section{Forma}

Lê-se na marca: H2OH! Há, aí, um sofisticado jogo linguístico, mas antes de abordá-lo, é preciso noticiar alguns fatos físico-químicos. "Existem mais de cem elementos e cerca de um milhão e meio de compostos, cada qual com a sua química” (Pimentel, 1974, p. 42) e a sua notação, uma representação que não resulta do acaso, mas de questões como a eletrovalência (Schaum, 1975, p. 99). Entre os compostos químicos, situase a água, constituída por dois átomos de hidrogênio e um de oxigênio (Mortimer, 1996).

O primeiro a propor que o solvente universal fosse composto por hidrogênio e oxigênio foi Lavoisier, na Academia de Ciência de Paris, em 1783.

Quando John Dalton propôs a teoria atômica em 1803, sugeriu a interpretação de que cada elemento fosse constituído por uma única espécie de átomos. Em uma reação química, os átomos de diferentes elementos poderiam combinar-se para formar moléculas (chamadas por Dalton de 'átomos compostos'), que seriam a menor unidade da substância composta. Para Dalton, um átomo de hidrogênio combinava-se com um átomo de oxigênio para formar a molécula de água - que teria a fórmula HO. Gay- Lussac, seguindo os trabalhos de Cavandish e Priestley, verificou que na formação da água dois volumes de hidrogênio combinam-se com um volume de oxigênio. Logo após a publicação desses resultados por Gay- Lussac, 
em 1808, Berzelius sugeriu a fórmula $\mathrm{H} 2 \mathrm{O}$ para a água. A ideia de fórmula química surgiu, portanto, como uma forma de expressar as quantidades das substâncias elementares que se combinam. (Mortimer, 1996, p. 19)

Da segunda metade do século XIX em diante, os químicos passaram também a representar espacialmente a molécula por meio das fórmulas. Na década de 1930, os desenvolvimentos trazidos pela física quântica introduziram dados mais precisos que a valência (capacidade que um átomo de um dado elemento tem de se combinar com outros átomos) para explicar o poder de combinação dos elementos, com o átomo sendo então seccionado em distintas áreas (o centro, neutro, e os elétrons, negativos, o orbitando). A partir desse momento, a ligação química

passa a representar um interação de natureza eletromagnética que ocorre entre os núcleos (carregados positivamente) e as eletrosferas (carregadas negativamente) de átomos vizinhos. O "tracinho" com que ligamos os átomos de hidrogênio e oxigênio na fórmula da água representa na verdade uma região do espaço ocupada por elétrons que estão sendo atraídos pelos dois núcleos vizinhos (o do oxigênio e o do hidrogênio). Ele não tem a realidade física de um elo material, apenas representa uma interação ou força elétrica que tem uma direção preferencial. [...] O fato de a primeira representação ser mais usual está ligado a sua simplicidade. No entanto, do ponto de vista de uma maior aproximação da natureza da ligação química, a segunda representação é mais conveniente. (Mortimer, 1996, p. 20, grifo nosso)

Desse modo, a simbologia química da água, fórmula de amplo conhecimento público e que prontamente aparece à mente das pessoas, é H2O, notação quase em homografia e, na fonética da língua portuguesa, em homofonia com $\mathrm{H} 2 \mathrm{OH}$ ! Basta pensar, tal qual anteriormente citado, na necessidade da Advocacia Geral da União em explicar juridicamente os elementos verbais responsáveis por distinguir a marca de bebida (H/!) e a fórmula, para assim garantir a validade do registro da $\mathrm{H} 2 \mathrm{OH}$ !

A decomposição de "H2OH!” em unidades menores revela dados ainda mais interessantes: tem-se que a marca contém não só a fórmula da água, mas também a palavra “OH!”, interjeição empregada em português para designar "surpresa”, “emoção”, “alegria”, “desejo” (Oh, 201-?). Simbolicamente, portanto, a marca "H2OH!” agrega água e emoção, com especial ênfase na última, tendo em vista o fato de a interjeição "OH!" estar situada na região de maior peso gráfico do signo visual.

Por fim, cumpre comentar as formas circulares que margeiam a letra "O". Ao indicar movimento da direita para a esquerda, isto é, da interjeição “OH!” em direção à fórmula da água, elas passam a simbolizar não apenas a presença do solvente universal e da emoção, mas a mistura de ambos.

\section{Opacidade}

O fato de a marca ser completamente opaca não cria, simbolicamente, efeitos relevantes, destacando-se as características qualitativas-icônicas e singulares-indiciais já apontadas. 


\section{Dimensão}

A dimensão é pequena em relação à escala humana e possibilita, como é desejável em uma marca, a visão rápida dos signos visuais.

\section{BREVE ANÁLISE}

Os aspectos simbólicos descritos acima caracterizam "um signo convencional que depende de um hábito nato ou adquirido" (Peirce apud Santaella, 2001, p. 263). Na semiótica peirceana, o símbolo descreve um tipo de relação que permite ao signo representar o objeto. Essa relação se dá "por meio de uma convenção de que ele será assim entendido, ou ainda por meio de um instinto ou ato intelectual que o toma como representando seu objeto, sem que qualquer ação necessariamente ocorra para estabelecer uma conexão factual entre signo e objeto". (Peirce apud Santaella, 2001, p. 263).

A capacidade simbólica da marca representar o solvente universal aliada a uma emoção específica que particulariza essa água é possível devido a um conjunto de fatores que determinam interpretantes gratificantes, práticos e lógicos. Como símbolos são legissignos, há uma lei que funciona como signo e que o fará ser interpretado. Essa lei pode gerar interpretantes de diferentes naturezas, variando conforme as qualidades particulares de cada réplica do legissigno. Como o símbolo se constitui através de seus interpretantes (Peirce, 1976), dedicaremos o final desse artigo à análise dos possíveis interpretantes produzidos pela marca $\mathrm{H} 2 \mathrm{OH}$ !, com o objetivo de elucidar a estratégia comunicativa que torna a marca representativa de um novo produto no mercado.

Como vimos, a associação entre cores, texturas, formas e dimensões sugere certa emoção que será vinculada à marca. Esses elementos qualitativos são assim interpretados porque há um hábito comum criado por experiências anteriores. As qualidades da marca adquirem características simbólicas, pois elas compõem e podem ser experimentadas em outros signos, formando aquilo que Peirce chama de experiência colateral. A experiência com outros signos, principalmente aqueles inseridos no mesmo contexto da marca, como águas minerais e refrigerantes, auxiliam no poder representativo desse signo, sugerindo que tal produto tem características semelhantes à água e aos refrigerantes.

Mas o elemento que mais caracteriza a função simbólica deste signo é o seu próprio nome. A notação química $\mathrm{H} 2 \mathrm{O}$, presente no nome da marca, funciona como uma réplica de um legissigno. Ela é uma atualização de uma lei química que determina que a fórmula $\mathrm{H} 2 \mathrm{O}$, dadas certas circunstâncias, deve representar a água. Essa regra determina um tipo de interpretação que liga o símbolo ao seu objeto e, portanto, envolve um interpretante lógico. A relação entre a notação H2O e o elemento água ocorre em função do conhecimento de uma convenção química.

Mas esse produto não é como o elemento químico água representado por "H2O”. Os caracteres “H!” modificam esse símbolo adicionando a ele certa particularidade. Como sabemos, o signo "H2O” é um legissigno e, assim como uma palavra, ele não é um individual, mas uma lei geral que é atualizada em diferentes instâncias. A lei determina a conformidade de suas réplicas e

por mais variações qualitativas que possam existir nas manifestações concretas, nas réplicas orais ou escritas de uma palavra 
ou de um padrão frasal, elas sempre se conformarão a uma invariância que é a da palavra ou do padrão como lei. (Santaella, 2001, p. 262-263)

A presença da notação química no nome $\mathrm{H} 2 \mathrm{OH}$ ! torna-o um sinsigno, uma réplica, ou uma forma corporificada do legissigno. Sua forma escrita ou falada, apesar de ter qualidade própria, não tem poder de transformar a capacidade representativa da lei.

Observamos que o acréscimo dos caracteres "H!” ao "H2O" transforma as qualidades desse signo escrito e falado. Apesar dessa variação qualitativa não modificar a lei que determina que "H2O" representa a composição atômica da água, ela modifica a ideia que temos de água na medida em que acrescenta a interjeição “OH!”.

Segundo Peirce (1932) apud Santaella (2001, p. 267),

um símbolo em si mesmo é um mero sonho, ele não mostra sobre o que está falando. Precisa estar conectado a seu objeto. Para esse propósito um índice é indispensável. [...] um índice é essencialmente um caso do aqui e agora, seu ofício sendo o de trazer o pensamento para uma experiência particular ou uma série de experiências conectadas por relações dinâmicas.

A fórmula da água presente na marca $\mathrm{H} 2 \mathrm{OH}$ !, particulariza a experiência com a água e indica uma relação existencial com esse elemento. Ela desempenha a função indicial dentro do símbolo, apontando para um tipo de água.

Mas além de apontar para a experiência particular, o índice incorpora uma determinada qualidade. Consequentemente, o símbolo também apresenta uma parte icônica responsável por produzir uma ideia geral do signo. Esse ingrediente icônico da generalidade simbólica é responsável por atualizar o hábito gerando significação. Ele qualifica o símbolo e pode ser subdividido em duas partes. Uma delas mostra a qualidade imediatamente percebida, enquanto, na outra, a qualidade funciona como uma atualização do conceito.

No caso analisado, as qualidades imediatamente percebidas, tanto pelo paladar quanto pela visão, não correspondem inteiramente ao elemento químico "H2O", pois nem o sabor do produto nem a grafia da embalagem coincidem com o H2O. Essa incongruência mostra que os caracteres "H" e "!", além de modificarem a grafia da palavra, indicam uma mudança também na qualidade do líquido ao qual o nome "H2OH!" se refere. As qualidades gráfica e gustativa, nesse caso, atualizam o conceito de "H2OH!”, mas não o de "H2O”. Portanto, essas qualidades são fundamentais para a distinção desses dois signos e para a introdução de um novo conceito no mercado, o da água saborizada.

Os símbolos podem ter interpretantes imediatos hipotéticos, categóricos ou relativos. O interpretante imediato mostra a potencialidade do signo para produzir interpretantes. Aqueles que são hipotéticos têm a capacidade de produzir uma hipótese. Os categóricos têm uma forma imperativa, são capazes de fazer previsões baseadas na hipótese e testálas. Já os relativos, apontam para um processo lógico de pensamento. Baseados nas dez tricotomias (Peirce, 2009, p. 477-491) e nas 66 classes de signos produzidas por elas (Borges, 2010), analisaremos como os interpretantes imediato, dinâmico e final podem ser gradativamente produzidos e qual relação eles estabelecem com o símbolo para entendermos melhor como um novo conceito pode ser criado. 
O interpretante imediato hipotético produz um interpretante dinâmico simpatético, isto é, um efeito criado devido a uma experiência similar com outro signo, uma experiência colateral. Esse efeito relaciona-se com o símbolo por sugestão, tem a capacidade de produzir um interpretante final gratificante e há apenas garantia de instinto nessa semiose. Por isso, o interpretante imediato hipotético produz uma hipótese, uma premissa lógica frágil, que é fundamental por iniciar o raciocínio lógico. No caso analisado, temos a produção de hipóteses baseada em todos os elementos simbólicos trabalhados anteriormente. Isto é, a hipótese de que se trata de uma água, dada pela fórmula $\mathrm{H} 2 \mathrm{O}$, e a de que esse líquido produz uma emoção, dada pela interjeição “OH!”.

O interpretante imediato categórico é um interpretante de secundidade, sua função é fazer previsões a partir das hipóteses e testálas. Interpretantes imediatos categóricos podem produzir interpretantes dinâmicos simpatéticos ou percussivos. No primeiro caso, não temos ainda previsões propriamente ditas, mas uma disposição a prever. No segundo caso, há uma previsão de fato baseada somente na expectativa com relação ao sabor, textura, sensação (refrescância) dada por experiências anteriores com a água e com a interjeição “OH!”. Essa previsão feita pelo objeto dinâmico percussivo pode seguir sendo apenas uma sugestão de interpretação do símbolo, ou pode tornar-se imperativa, isto é, gerar uma relação de fato entre signo e interpretante. Essa relação tem a forma de uma experiência (que pode ser tátil, visual ou gustativa) que confirmará ou não as previsões. As previsões confirmadas produzirão um resultado interpretativo (interpretante final) gratificante e a semiose é instintiva. Já as previsões não confirmadas levarão a um resultado interpretativo prático, isto é, deve ocorrer uma ação mental. Ela pode produzir um novo termo, introduzindo o nome "H2OH!" na mente. Ou produzir uma proposição na qual o termo é associado a qualidades próprias do signo dadas por experiências de qualquer natureza com ele.

Quando há produção de um termo, há outra vez na semiose a garantia de instinto, pois apesar das experiências com o signo, não foi agregada a ele nenhuma qualidade específica, particular, de fato, além daquela que o identifica como um termo. Podemos pensar que a experiência tenha sido apenas visual criando uma ideia do produto, possibilitando sua identificação e diferenciação, mas sem agregar a esse nome qualidades gustativas. No caso da produção de uma proposição, a semiose experimental, ou garantida de experiência, associa qualidades próprias e experienciadas do signo ao termo. Para ter essa capacidade, a experiência com o signo deve ser mais ampla. Ela pode ser uma experiência direta, como a gustativa ou olfativa, mas também pode ser uma experiência indireta dada por um relato descritivo do sabor dessa bebida.

A produção desses interpretantes leva ao conhecimento do signo. A marca $\mathrm{H} 2 \mathrm{OH}$ ! passa a ser conhecida e aponta para a produção de um interpretante imediato relativo, capaz de significar determinado produto. Essa capacidade significativa varia em graus de determinação. Quando o interpretante imediato relativo é seguido por um interpretante dinâmico simpatético, temos um significado menos preciso, mais abdutivo e baseado em expectativas. Quando dele segue um interpretante dinâmico percussivo, temos a produção de significado baseada em deduções e induções. Assim, o significado é construído tornando-se usual na mente interpretadora. Novamente, sendo usual, o interpretante pode estabelecer uma relação apenas sugestiva com o signo, dada por semelhança de qualidades, produzindo uma abdução. Ou ele pode estabelecer uma 
relação baseada em experiências que é chamada imperativa e que testa a abdução por meio de processos dedutivos e indutivos. Como resultado desses testes, alcançamos um interpretante final pragmático, um resultado interpretativo que produz autocontrole.

Nessa etapa, voltamos ao objeto de análise desse artigo, pois percebemos que após uma série de experiências com o produto e da relação dessas experiências com as expectativas que são constantemente geradas, o consumidor constrói uma ideia consolidada e consciente da marca. A produção de autocontrole mostra que houve um processo de racionalização, que torna possível a tomada de decisão por meios lógicos. Novos termos e proposições podem ser criados e, por fim, há possibilidade de produção de um argumento. Quando o signo e o interpretante final (ou resultado interpretativo) estabelecem uma relação do tipo argumentativa, torna-se possível a criação de um hábito interpretativo, a consolidação de um conceito, e há garantia formal na semiose.

\section{CONSIDERAÇÕES FINAIS}

Por meio da análise, descrevemos aspectos qualitativos, singulares e simbólicos da marca $\mathrm{H} 2 \mathrm{OH}$ ! capazes de mostrar a complexidade de um signo que desliza livre e promiscuamente entre categorias sígnicas. As questões impostas por esse novo produto introduzido em um mercado no qual não há uma categoria que contemple suas características mostra a capacidade de um signo de tornar-se significativo. Não são apenas aspectos qualitativos nem a pura experiência com o produto, tampouco o poder simbólico da fórmula química agregada ao nome que produzirão esse novo conceito de água saborizada proposta pela $\mathrm{H} 2 \mathrm{OH}$ ! Há um intrincado percurso semiótico que possibilita esse significado e que buscamos descrever neste artigo.

Esse percurso semiótico mostra que o signo não pertence a uma categoria sígnica, nem pode ser explicado pelo poder representativo de uma só classe. Está na passagem de uma classe a outra o potencial dos signos para significarem. Por isso, deslizamos entre as categorias sígnicas de Peirce para mostrar como essa marca, que também desliza entre categorias mercadológicas (entre água e refrigerante), se estabelece no mercado, criando um novo conceito de bebida.

\section{REFERÊNCIAS}

ARAÚJO, E. F. A lógica heurística/persuasiva do design gráfico. Dissertação de mestrado defendida no Programa de Estudos Pós-Graduados em Comunicação e Semiótica da PUC-SP, 2005.

Design gráfico: descoberta e convencimento. In: Caderno da 7ạ Jornada de Estudos Peirceanos. São Paulo: PUC-SP, p. 83-95, 2004.

BORGES, P. M. Mensagens cifradas: a construção de linguagens diagramáticas. Tese de doutorado defendida no Programa de Estudos Pós-Graduados em Comunicação e Semiótica da PUC-SP, 2010.

CHIACHIRI, R. A estratégia da sugestão na publicidade. Uma análise semiótica. São Paulo: Academia Editorial, 2006.

Aspectos sugestivos na comunicação publicitária. In: Caderno da 7ạ Jornada de Estudos Peirceanos. São Paulo: PUC-SP, p.75-82, 2004.

GIANNOTTI, M. Apêndice. In: GOETHE, J. W. Doutrina das cores. Apresentação, seleção e tradução Marco Giannotti. São Paulo: Nova Alexandria, 1996.

GOETHE, J. W. Doutrina das cores. Apresentação, seleção e tradução Marco Giannotti. São Paulo: Nova Alexandria, 1996. 
GOLDMAN, S. Psicodinâmica das cores. 3. ed 2v. Porto Alegre: LaSalle, 1964.

GUIMARÃES, L. A cor como informação: a construção biofísica, linguística e cultural da simbologia das cores. São Paulo, Annablume, 2000.

MORTIMER, E. F. O significado das formulas químicas. Química nova na escola, São Paulo, v. 3, p. 19-21, maio 1996

OH. In: DICIONÁRIO brasileiro da língua portuguesa. São Paulo: Michaelis, 201-? Disponível em: http://bit.ly/2oeFso9. Acesso em: 24 jun. 2010.

O "LIGHT" caducou. Revista Veja, São Paulo, 31 jan. 2017. Disponível em: http://abr.ai/2nOiUQF. Acesso em: 20 jun. 2010.

PEIRCE, C. S. Collected papers of Charles S. Peirce. Cambridge, Mass.: Harvard Univ. Press, 1932. The essential Peirce. Selected Philosophical Writings. vols. 1-2. Bloomington, IN: Indiana University Press, 2009.

The new elements of mathematics. v. 1. Hague. Atlantic Highlands, N.J: Mouton Publishers. Humanities Press, 1976.

PEPSICO prepara defesa contra suspensão da H2OH! O Estado de S. Paulo, São Paulo, 16 out. 2006. Disponível em: http://bit.ly/2mAiUSn. Acesso em: 20 jun. 2010.

PIMENTEL, G. C. Química: um tratamento moderno. São Paulo: Edgard Blucher, 1974.

SANTAELLA, L. Matrizes da linguagem e do pensamento: sonora, visual, verbal. São Paulo: lluminuras, 2001.

Semiótica aplicada. São Paulo: Pioneira Thomson Learning, 2002.

SANTAELLA, L.; NÖTH, W. Estratégias semióticas da publicidade. São Paulo: Cengage Learning, 2010.

SCHAUM, D. Química geral: resumo da teoria, 385 problemas resolvidos, 750 problemas propostos. São Paulo: McGraw-Hill, 1975. 